\title{
Nuevas Dimensiones, Nuevas Adicciones: La Adicción al Sexo en Internet
}

\section{New Dimensions, New Addictions: The Internet Sex Addiction}

\author{
Silvia Sánchez Zaldívar \\ Hospital Universitario Fundación Alcorcón
}

\author{
Itziar Iruarrizaga Díez \\ Universidad Complutense de Madrid
}

\begin{abstract}
Resumen. La red es interminable: se puede ir a cualquier sitio, encontrar cualquier cosa, ser cualquier persona. Teclear la palabra sexo en google arroja 96 millones de resultados. La red está cambiando nuestra forma de comunicarnos y relacionarnos, nos permite construir coordenadas espacio-temporales antes incompatibles. La adicción a Internet no está reconocida en la actualidad como un trastorno en el DSM-IV-TR ni en la CIE-10. Las dos modalidades de adicción a internet con contenido sexual serían el cibersexo y la pornografía. En el cibersexo se experimenta estimulación sexual mientras se mantiene contacto sexual con otra persona. No existe un perfil de usuario, es una conducta extendida y puede tener su aspecto positivo (para determinadas comunidades, para personas con menos habilidades sociales, para condimentar la vida sexual) y su aspecto negativo (adicción, pérdida de control, problemas de pareja y familiares). Es un sexo seguro, anónimo, sin complicaciones. La pornografía en Internet permite el voyeurismo, la visualización de cualquier tipo de prácticas, el uso de modelos reales no profesionales y el espionaje de nuestras conductas a través de los códigos IP. Estas actividades sexuales en la red parecen estar alimentadas por el motor "Triple A": accesibilidad, anonimato, asequibilidad. Hay que evaluar al individuo, a la pareja y las actividades en Internet. No hay tratamiento psicológico ni farmacológico probado pero los programas cognitivos conductuales y técnicas usadas en otras adicciones son provechosas. Existe una gran comorbilidad. El objetivo del tratamiento es el uso adaptativo de Internet. Los profesionales de la salud debemos anticiparnos y aprender sobre estas conductas, diseminar adecuadamente la información para no lanzar mensajes simplistas, proporcionando marcadores y desarrollar estudios, investigaciones y programas de prevención.
\end{abstract}

Palabras clave: sexo, adicción, Internet, cibersexo, pornografía.

\begin{abstract}
The network is endless: going anywhere, finding anything, being anyone. Typing the word sex on Google gives a figure of 96 million results. The network is changing our way of communication and relation; we can construct space-time coordinates before incompatible. Internet addiction is not recognized as a disorder in DSM-IV-TR or ICD-10. Both types of Internet addiction with sexual content are cybersex and pornography. Cybersex consists in experiencing sexual stimulation while maintaining sexual contact with other person. There is no user profile, it is a widespread behaviour and might have a positive aspect (in some communities, persons with fewer social skills, to spice sex life) and a negative aspect (addiction, loss of control, marital and family problems). Sex is safe, anonymous and
\end{abstract}

La correspondencia sobre ese artículo deberá dirigirse a la primera autora. Hospital Universitario Fundación Alcorcón. Avda. Budapest s/n. 28922 Alcorcón (Madrid). E-mail: ssanchezz@fhalcorcon.es 
without complications. Internet pornography voyeurism allows the visualization of all types of practices, the use of real models not professional and to spy our behaviour through the IP code. These sexual activities on the network seems to be powered by the "Triple A" engine: accessibility, anonymity, affordability. We must assess the individual, the couples and the Internet activities. There is no proven pharmacological or psychological treatment but cognitive behavioural programs and techniques used in other addictions are helpful. There is large comorbidity. The goal of treatment refers to the adaptive use of Internet. Health professionals should be in advance and learn about this kind of behaviours, as well as to disseminate the information appropriately not launching simplistic messages, providing markers and developing studies, research and prevention programs.

Key words: sex, addiction, Internet, cybersex, pornography.

\section{¿Existe la adicción al sexo en internet?}

Stricto sensu, no existe. Hoy por hoy, no está reconocido este trastorno como tal en el DSM-IV-TR (Diagnostic and Statistical Manual of Mental Disorders, fourth edition, Text Revision "Manual diagnóstico y estadístico de los trastornos mentales, cuarta edición, revisión de texto") ni en la Clasificación Internacional de Enfermedades, décima revisión (CIE-10). No se contemplan los trastornos adictivos como un círculo patológico autónomo. Las adicciones químicas son clasificadas como abusos de sustancias, las adicciones sociales son ignoradas casi en su totalidad. La ludopatía y la cleptomanía se clasifican como trastornos del control de impulsos. En este entorno algunas orientaciones han equiparado la adicción con el abuso y otras con un trastorno relacionado con la pérdida en el control de los impulsos.

Muchos autores abogan para que se incluya en la próxima revisión de esta Biblia, en 2012, igual que otras muchas patologías que aún no están tipificadas. Una cuestión legítima de su ausencia, de todas formas, es que la última revisión del DSM-IV-TR se publica en el año 1994 y la penetración de la red todavía es escasa. Otras voces argumentan que la tendencia de algunos profesionales de la salud mental y de algunos investigadores es etiquetar todo lo que ven como potencialmente nocivo con una nueva categoría diagnóstica, objetan que la posible clasificación de la adicción a internet como entidad nosológica diferenciada (ya sea en su variante sexual $\mathrm{u}$ otras) está llena de confusión entre causa y efecto, replican que la mayor parte de las personas que se consideran adictos a internet son probablemente víc- timas del deseo de no querer hacer frente a otros problemas en sus vidas (depresión, ansiedad, problemas de salud o discapacidad, de relación) y razonan que el uso compulsivo ya está cubierto por otras categorías diagnósticas y que, por tanto, el tratamiento será similar: lo importante no es la tecnología (ya sea internet, el teléfono, o la televisión) sino el comportamiento, que será igualmente tratado mediante el empleo de las técnicas cognitivo-conductuales más eficaces. Yendo más allá, Grohol (2008) señala que existen muchos errores metodológicos en las investigaciones llevadas a cabo sobre la adicción a Internet, por ejemplo, estudios de caso único, deficiencias en las propiedades psicométricas de los instrumentos de evaluación empleados, o ausencia de modelo teórico. Unos proclaman que se reconozca una realidad innegable y otros que se cuestionen y clasifiquen adecuadamente determinadas entidades diagnósticas. El debate está abierto y lleno de matices.

\section{La actualidad en datos}

Los enganches adictivos al alimento, el sexo, las compras, el juego, el trabajo e internet han constituido una plaga en las dos últimas décadas, el denominador común de las sociedades occidentales es que se han erigido como una auténtica civilización adictiva. La gran disponibilidad de los objetos adictivos, la alta incidencia de situaciones como el estrés, la soledad, la depresión son innegables caldos de cultivo. Vivimos en tiempos exponenciales. Más de mil millones de personas en el mundo tienen acceso a internet. Aproximadamente 220 millones de nortea- 
mericanos tienen acceso a internet y el $40 \%$ tienen acceso de alta velocidad. El número de mensajes de texto enviados cada día es mayor que la población del mundo. Si MySpace fuera un país, el número de usuarios registrados que lo convertirían en el undécimo país más grande del mundo. (Conner, 2008).

La utilización de internet ha crecido en menos tiempo más rápido que cualquier tecnología en la historia, incluido el teléfono, la televisión, los ordenadores, los videojuegos y reproductores de CD. La red proporciona a los usuarios todos los días, principalmente por la web: correo electrónico, mensajería instantánea, chat en vivo y la capacidad de adquirir bienes y servicios en línea. Las personas pueden ir a cualquier parte, buscar y encontrar casi cualquier cosa, realizar diversas actividades y, entrecomilladamente, "ser lo que quieren ser", permaneciendo en su propia silla exploran un sinfín de actividades, no es necesario que estén con una persona real y sus conductas no están marcadas por determinadas consecuencias ni impedimentos sociales. En España, por ejemplo, según el Instituto Nacional de Estadística, en el año 2008 el 51,0\% de los hogares españoles tenía acceso a la red, frente al $44,6 \%$ del año anterior. En nuestro país existen 7,7 millones de viviendas familiares que tienen acceso a internet, con un incremento de más de un millón de hogares respecto al año 2007. La proporción de uso de tecnologías de información por la población infantil (de 10 a 15 años) es, en general, muy alta. Así, el uso de ordenador entre los menores es prácticamente universal $(94,1 \%)$ mientras que el $82,2 \%$ utiliza internet. (Instituto Nacional Estadística, 2008).

Este medio sacia la curiosidad que posee el hombre por naturaleza, le permite socializarse, evadirse, recrearse o refugiarse. La red es interminable, interactiva, con un sin fin de imágenes e información y de otras personas detrás..., es decir, la salsa de la vida. Pero bien es verdad que estas actividades gratificantes e inofensivas (igual que la comida, las compras, el juego, el sexo, el trabajo) pueden convertirse en una necesidad absoluta que esclaviza a la persona y le conduce a una enfermedad mortificante, progresiva, llena de riesgos como es la adicción. Cuando la afición a un objeto se torna una necesidad es cuando aparece la adicción. La diferencia entre una afición y una adicción viene marcada no sola- mente por la intensidad y la frecuencia sino también por la pérdida en el autocontrol.

El trastorno de adicción a internet ocurre a nivel internacional pero lógicamente se da más en países donde el acceso al ordenador y la tecnología están más extendidos. No existen estudios en muchos países sobre la prevalencia de la adicción a internet y sus factores de riesgo asociados, explicados en parte por la ausencia de instrumentos psicométricos de evaluación y de estudios rigurosos. La prevalencia de la adicción a internet varía extensamente, en una revisión reciente sobre su prevalencia entre la población general estadounidense se relata una estimación de entre el 0.3 y el $0.7 \%$ (Shaw y Black, 2008). En otros casos se habla de cifras más altas, según un estudio de la Escuela de Medicina de la Universidad de Stanford (California) presentado en la 28 Reunión Anual de la Asociación de Trastornos de Ansiedad de América. (Aboujaoude, 2008), cerca del $1 \%$ de la población general de los Estados Unidos muestra adicción o un uso problemático de internet. En otros países los datos son más alarmantes, en China el $13.7 \%$ de usuarios chinos adolescentes pueden cumplir los criterios de adicción a internet, aproximadamente 10 millones de adolescentes. (Block, 2008).

Según las estadísticas proporcionadas por el propio Google a través de los motores de búsqueda de internet, la palabra más buscada en internet es sexo. A la cabeza los países africanos, en especial los del norte de África, la África subsahariana, Egipto, Turquía y la India. (http://www.reuters.com). La pornografía en internet ha crecido hasta convertirse en un negocio multibillonario. Según el Economic Times, la pornografía es la fuente más rentable de ingresos generados en internet (Jaychandran, 2006). Las estadísticas de los filtros de revisión de internet atestiguan que la industria de la pornografía mueve 57 mil millones de dólares en todo el mundo, 12 mil millones de dólares solamente en los Estados Unidos. Según estas mismas estadísticas los ingresos de la pornografía son mayores que todos los ingresos combinados de todos los profesionales de fútbol, béisbol y baloncesto en los Estados Unidos. Hay alrededor de 4,2 millones de sitios Web pornográficos que constituyen el $12 \%$ del total de sitios Web, 372 páginas pornográficas con millones de visitas, que constituyen el $25 \%$ del total de solicitu- 
des de búsqueda (Ropelato, 2006). Con tal multitud y abundancia de material sexualmente explícito en la web, la adicción a la pornografía en línea se ha convertido en el crack de internet (Cooper, 1997).

El uso de nuevas tecnologías en nuestra sociedad también afecta a nuestra profesión, tanto por el estudio de casos como por la producción científica. El año en que más producción se llevó a cabo fue el 2004, en el que se publicaron 42 artículos sobre aficiones generales que incluyen comunicaciones y tecnologías de la información y otras aficiones conductuales (internet, videojuegos, teléfono móvil). Estados Unidos, China, Reino Unido fueron los países a la cabeza de la producción científica y la afición por internet era el aspecto más estudiado (el $85.3 \%$ ), seguido de la afición a los videojuegos (el $13.6 \%$ ) y teléfonos móviles (el 2.1\%) (Carbonell et. al, 2009). No obstante, debemos destacar que estos estudios en la actualidad tienen grandes limitaciones. La primera y más importante, y aunque suene redundante, es la propia limitación o delimitación del trastorno, aún no constituye una identidad nosológica en sí y afecta tanto a la propia evaluación como a su tratamiento. Además, las encuestas adolecen del rigor metodológico y estadístico, las muestras con las que se trabajan son reducidas, parciales y fragmentadas, y existe una gran comorbilidad. No hay datos anamnésicos suficientes ni estudios realizados con largas series de pacientes, son cuestiones asociadas a la aproximación del conocimiento sobre un concepto, desorden, trastorno que estarán presentes mientras se desarrollan los modelos conductuales que sostengan la adicción a internet.

\section{La adicción a internet}

El trastorno de dependencia de la red se ha conocido con muchos nombres: desorden de adicción a internet -Internet Addiction Disorder (IAD)(Goldberg, 1995), uso compulsivo de internet (Moran-Martin y Schumacker, 1997), o uso patológico de internet- Pathological internet Use (PIU)(Young y Rodgers, 1998). Aunque, como ya se ha explicado, no está reconocida oficialmente, esta nueva adicción ha atraído la atención creciente en los medios de comunicación y entre investigadores, siendo ésta paralela al propio crecimiento del uso del ordenador y del acceso a internet. La tarea de definir lo que es la adicción a internet es algo que ya de partida nos supone un problema. Con lo ya expuesto, podemos decir que el uso de internet (como cualquier otro comportamiento) es susceptible de crear una adicción en función de la relación que el sujeto establezca con ese uso. En la tabla 1 se refieren los criterios que Golberg (1995) propone para el diagnóstico del desorden de adicción a internet, basados en los criterios diagnósticos del abuso de sustancias.

Tabla1. Criterios para el diagnóstico de adicción a Internet (Golberg (1995)

Un patrón desadaptativo de uso de internet, que conlleva un deterioro o malestar clínicamente significativo, expresado por tres o más de los ítems siguientes en algún momento de un periodo continuado de 12 meses:

- Tolerancia, definida por cualquiera de los siguientes ítems:

- Una necesidad de incrementar notablemente la cantidad de tiempo en internet para lograr satisfacción.

- Notable disminución de los efectos con el uso continuado de la misma cantidad de tiempo en internet.

- Abstinencia, manifestado por cualquiera de los siguientes ítems:

- Cesación o reducción de un uso de internet que ha sido grande y prolongado.

- Dos o más de los siguientes, desarrollados algunos días durante un mes antes: (agitación psicomotora, ansiedad, pensamientos obsesivos acerca de lo que estará sucediendo en internet, fantasías o sueños acerca de internet, movimientos de tecleo voluntarios o involuntarios, los síntomas causan malestar o deterioro en las áreas sociales, laborales u otra área importante de funcionamiento).

- El uso de internet o un servicio similar esta dirigido a aliviar o evitar los síntomas de la abstinencia.

- Se accede a internet con más frecuencia o por periodos más largos de lo que inicialmente se pretendía.

- Deseo persistente o esfuerzos infructuosos de controlar o interrumpir el uso de internet.

- Se emplea mucho tiempo en actividades relacionadas con el uso de internet (e.g. comprando libros sobre internet, probando nuevos navegadores, indagando proveedores de internet, organizando ficheros o descargando materiales).

- Actividades sociales, ocupacionales o recreativas se dejan o reducen a causa del uso de internet.

- Internet se continúa usando a pesar de saber que se tiene un persistente o recurrente problema físico, social, ocupacional o psicológico que parece ser causado o exacerbado por el uso de internet (privación de sueño, dificultades maritales, llegar tarde a las citas por las mañanas, abandono de los deberes profesionales, o sentimientos de abandono de personas significativas). 
A su vez, Young et al. (1999) y Greenfield (1999b) distinguen cuatro modalidades de adicción a Internet: 1. Adicción Cibersexual (adicciones a las salas de chat para adultos o ciberpornografía); 2 . Adicción a la Ciber-relación (amistades hechas en línea en salas de chat, MUDs, o grupos de noticias que sustituyen la vida real, los amigos y la familia, esto incluye también los ciberaffairs); 3. Las compulsiones de la red (búsqueda de páginas web, en la mayoría de los casos comerciales, juegos de azar, comercio electrónico, subastas); y 4. Buscadores de información y vagabundos electrónicos (robots de búsqueda, FTP, TELNET, simplemente navegar por la red sin una meta específica y buscar información sobre un tema de interés.

Las diversas modalidades en que puede presentarse la adicción a internet deben ser también objeto de análisis. Las diferentes clasificaciones que se han propuesto se basan en dos características: la aplicación que se utiliza y el tipo de contenido al que se accede. Algunas de estas modalidades se solapan entre sí y en otras no queda claro cuál es el objeto de la adicción. En este sentido, resultaría fácil encontrar personas que utilizan los chat para lograr satisfacción sexual o ludópatas que emplean internet para implicarse en juegos de azar: el límite de las modalidades entre sí y con otros trastornos no está claramente definido. En la mayoría de estas modalidades lo que existe es un trastorno psicológico o carencia que se expresa a través de internet. Con el avance de la investigación se debe hacer evidente que en la mayoría de las ocasiones la adicción a internet no es sino un trastorno secundario a otros como la fobia social, depresión, adicción al sexo o a diversas parafilias. Internet puede fácilmente ser el objetivo de comportamientos obsesivo/compulsivos, reforzados por la gran cantidad de recursos que se pueden encontrar en la red para alimentar otras adicciones o compulsiones (Griffiths, 1998).

Entonces ¿a qué se hacen adictos los adictos a internet? ¿Es al contenido al que acceden o es al internet en sí? Pratarelli et al. (1999), utilizan el término adicción al ordenador/internet, y lo definen como un fenómeno o desorden que depende tanto del medio como del mensaje, sin inclinarse a favor de ninguno. Otros autores (Echeburúa, 1999; Griffiths 1998) han señalado que internet podría ser en la mayoría se los casos un medio o lugar donde alimentar otras adicciones o trastornos ( $\mathrm{p}$ ej. adicción al sexo, ludopatía o parafilias), aunque también señalan que existen casos de adicción a internet por sí mismo. En lo que sí existe un mayor consenso es en los problemas potenciales que su uso abusivo provoca: descuido personal, aislamiento y evitación de relaciones interpersonales, depresión, pérdida de productividad, problemas matrimoniales, adicción sexual, problemas laborales, fracaso escolar, pérdidas económicas.

\section{Donde el sexo e internet se cruzan}

¿Masturbación?, ¿sexo?, ¿chutes de cariño a golpes de ratón?, ¿seducción con palabras en el chat o sexo puro?, ¿relaciones cibersexuales?, ¿travestismo electrónico?, ¿sexo seguro?, ¿pornografía y acoso sexual?, ¿pederastia? Todo esto y mucho más, existe cuando se cruzan sexo e internet. Las nuevas tecnologías de la información llevan ya tiempo proporcionando las condiciones materiales apropiadas para establecer interacciones y vínculos en nuevos espacios, pero los avances tecnológicos no aparecen en el vacío ni como productos acabados sino como una síntesis de procesos socioeconómicos e históricos en constante transformación. Y lo mismo podríamos decir sobre las distintas formas de relacionarnos social y sexualmente, bien sea en espacios físicos o virtuales. (Cavia y Gordo, 2002). La red permite construir coordenadas espacio-temporales que antes resultaban incompatibles, precipita comunicaciones, emociones, deseos e intrigas entre personas distanciadas geográficamente e identidades diferentes. Es un medio que, aunque ensalzado por su posibilidad de comunicación y de establecer comunidades alternativas, cada vez se considera más relacionado con la falta de compromiso y con el exceso de individualismo. Algunos entienden que los ordenadores y las tecnologías de la comunicación representan la deshumanización de la sociedad, mientras que otros, en el sentido opuesto, se empeñan en enfatizar sus virtudes y progresos. Búrdalo (2000), por ejemplo, señala que desde la antigüedad el hombre ha manifestado y comunicado sus apetitos y tendencias sexuales de las más diversas formas, y que esta 
época bien puede estar marcada por un e-sex y sexo virtual.

Dada la amplia disponibilidad de material sexualmente explícito en línea, la adicción sexual a internet es la forma más común de comportamiento problemático en la red. La adicción al sexo en internet generalmente implica visualizar, descargar, comprar pornografía en la red y participar en salas de juego para adultos con diferentes fantasías. Las dos modalidades destacadas de adicción a internet con contenido sexual serían las ciber-relaciones (o usos de Chat) y la adicción cibersexual (o uso de pornografía y salas de adultos).

El cibersexo es indudablemente un componente destacado de gran parte de los chats y foros de discusión electrónicos. Los internautas pueden embarcarse en todo tipo de prácticas sociales y sexuales en la red. Recientemente, Daneback et al. (2005) han definido el cibersexo como cuando dos o más personas simpatizan en una conversación sexual en línea con el fin de obtener placer sexual y que puede incluir, o no, la masturbación. Es un fenómeno creciente con un impacto significativo sobre los usuarios. Algunos autores lo señalan como un espacio a medio camino entre la fantasía y la acción, y de la suplantación de lo real por lo simbólico (Ross, 2005). En los chats, por ejemplo, lo importante en muchas ocasiones de encuentro casual no es tanto lo que dice el interlocutor sino cómo se imaginan a sí mismos los individuos, y no es tanto el qué se dice sino el cómo emerge y se narra. Mientras algunos autores consideran apropiado hablar del término ciber en este contexto, más importante es la cuestión de si es apropiada la palabra sexo en el mismo contexto. El sexo en el cibersexo es una forma tecnológica de masturbación y una manifestación de la líbido que en realidad implica la taylorización de la líbido del cuerpo, es un deseo de órganos sin cuerpo (Eerikäinen, 2003).

A diferencia de otras relaciones sexuales, el cibersexo no es motivo de sanción cultural en la medida que está exento casi por completo de complicaciones sentimentales, estas finalizan al apagar el ordenador y volver a la vida cotidiana (Búrdalo, 2000). Las personas implicadas en el cibersexo minimizan la importancia y el impacto de su comportamiento, dicen que lo que es solo en la red no es realmente sexo; sin embargo, paradójicamente algunos adolescentes se están convirtiendo en adictos sexuales sin necesariamente haber practicado nunca una relación coital. Asimismo, el ciberespacio dota de nuevas posibilidades también a las comunidades no heterosexuales, gays y lesbianas que fuera del ojo social pueden expresar su sexualidad más libremente, permitiéndoles interaccionar con otros con intereses afines. En este sentido, McKenna y Bargh (1998), en un estudio realizado con grupos de discusión, encontraron que internet permite a aquellas personas que se sienten estigmatizadas (por razones de sexo o ideología) sentir la pertenencia al grupo virtual como una señal de identidad, llegar a una gran autoaceptación y, en última instancia, revelar a sus familiares y amigos sus necesidades; sin embargo, también la adicción al cibersexo puede erosionar, e incluso sustituir a las auténticas relaciones íntimas. El mantenimiento de relaciones de pareja se complica si el sujeto permanece compulsivamente en internet durante horas.

La pornografía y los chat o salas de adultos permiten a las personas experimentar y explorar sentimientos sexuales en privado y complacer sus fantasías, que se pueden adaptar a cualquier necesidad o deseo sexual imaginables (homosexualidad, servidumbre, bestialismo, fetichismo, incesto, etc.) Como señala Young (2001), para algunas parejas y usuarios individuales estas salas de chat pueden ofrecer una nueva forma de condimentar su vida sexual, pueden explorar nuevas formas de intimidad y sexualidad en su relación y pueden ser una buena salida para explorar la sexualidad en un entorno seguro y privado; sin embargo, para el adicto estas fantasías, chat y roles pueden conducir a una mayor tentación. En este sentido, Durkin y Bryant (1995) señalaron que el cibersexo permite a una persona operacionalizar las fantasías sexuales que, de otra manera, podrían haber autoextinguido si no fuera por el reforzamiento y feedback inmediato que proporcionan estas interacciones en línea. De un modo similar, Van Gelder (1991) advirtió de los peligros del empleo de internet para obtener pornografía infantil, ponerse en contacto con jóvenes, o falsificar la identidad sexual de alguien con intenciones inofensivas o malévolas.

La pornografía en internet se diferencia notable- 
mente de la que existe en los soportes clásicos (revistas y videos) porque no se basa exclusivamente en la exhibición de genitales sino que permite también el voyeurismo. Mediante webcams instaladas hasta en los lugares más íntimos, los usuarios pueden ingresar en determinadas intimidades, surgiendo una pornografía que no se basa en el sexo explícito, sino en lo mórbido de poder ver sin ser visto. También, la pornografía de internet se distingue de la que se difunde en otros medios, porque la tecnología informática permite espiar a sus usuarios a lo largo de todo el trayecto de su navegación virtual. Esto implica que la empresa dueña del sitio web pornográfico sabe exactamente cuántas veces éste ha sido visitado, a qué fotos y videos el usuario le dedicó más tiempo, y mediante el código IP podrá incluso detectar dónde vive, de manera tal que quienes administran estas páginas son capaces de construir un perfil de usuario bastante preciso para cada uno de sus clientes (relacionado con esto último por ejemplo, está la enorme variedad de pornografía que se ofrece en la red, apareciendo toda una suerte de pornografía especializada para cada una de las parafilias conocidas y, probablemente, por conocer). Otra característica adicional y propia de la pornografía de internet es que no sólo está constituida por las fotos o videos que toman profesionales a modelos, sino que cada vez hay más internautas que toman fotos o filman situaciones relacionadas con el sexo y luego las envían, sin esperar remuneración alguna, a los sitios web XXX. (Ramos, 2006).

El consumo de pornografía por lo general siempre se hace bajo el secreto de la intimidad y esta es más difícil de alcanzar cuando el ordenador es de uso familiar y ocupa un espacio público dentro de la casa. Las empresas dedicadas a la distribución de pornografía a través de internet han solventado estos problemas ofreciendo a sus clientes la posibilidad de gozar de los videos o fotos que compran a través de sus teléfonos móviles mediante la tecnología SMS. La pornografía es legal en casi todas los países del mundo pero hay cierta pornografía, como la infantil o la que proviene del video snuff -violaciones y/o crímenes reales filmados sin mediar truco cinematográfico- (Gubern, 2000), que está prohibida a nivel mundial y su exhibición pública resulta complicada por quienes la han convertido en jugoso negocio.
Estos individuos utilizan medios de comunicación privados como el correo electrónico, habiéndose creado verdaderas redes mundiales de sórdidos consumidores de pornografía que, a su vez, con frecuencia se convierten también en productores de la misma, es decir en violadores y/o abusadores de niños. En internet la pornografía alienta no sólo lo mórbido sino que también permite, gracias a su relativo anonimato, los más execrables delitos.

Internet puede también llegar a ser un medio para propiciar conductas adictivas sexuales, desde obtener material pornográfico ilegal a facilitar delitos sexuales (Galbreath \& Berlin, 2002; Griffiths, 2001). Las tecnologías cada vez más avanzadas en internet con potentes ordenadores, exploradores, cámaras digitales abren nuevas posibilidades de crimen para el delincuente cibersexual. Estos delincuentes cibersexuales usan ordenadores para ver, almacenar, producir, enviar, recibir y/o distribuir por ejemplo a niños diversas formas de pornografía, igualmente pueden atraerlos para perseguirlos o comunicarse con otros delincuentes sexuales. Proporciona un método para el delincuente cibersexual afectando a la víctima sin incurrir en ningún tipo de contacto físico. (Bowker y Gray, 2004).

\section{Señales de advertencia de la adicción al sexo en internet}

Una vez destapada la botella en algunas ocasiones y para algunas personas puede ser difícil cerrarla, a medida que los usuarios empiezan a sentirse cómodos con las formas de sexo virtual pueden experimentar cambios en su comportamiento o señales de advertencia que pueden darnos la pista de que se han hecho adictos (Young, 2001):

- Habitualmente gastan cantidades significativas de tiempo en las salas de chat y mensajería privadas con el único propósito de encontrar pornografía en línea o cibersexo.

- Se sienten ansiosos por encontrar actividades en línea sobre sexo.

- Participan en fantasías sexuales que no suelen llevarse a cabo en la vida real.

- Prevén la próxima sesión en línea con la expectativa de que van a encontrar excitación sexual 
o gratificación. A menudo pasan de cibersexo a sexo telefónico o a sexo real.

- Esconden sus interacciones en línea a su entorno más significativo.

- Sienten culpa o vergüenza acerca del uso de la red.

- Se masturban mientras buscan pornografía o con el chat erótico.

- Invierten menos tiempo en sus relaciones sexuales reales o prefieren la pornografía o el cibersexo como principal forma de gratificación sexual.

\section{Mecanismos de la adicción al sexo en internet}

No deja de sorprender que un medio tan aparentemente frío y mediatizado reciba tanta atención e, incluso, adicción. ¿Qué nos incita a adentrarnos en él e intercambiar con desconocidos líneas de intimidad, deseos y angustias mediadas por un ordenador? ¿A qué se debe que el amor y la sexualidad estén tan a flor de piel en estos territorios supuestamente insensibles e inhumanos? Estas actividades sexuales en la red (on line sexual activities OSA) parecen estar alimentadas por el motor "Triple A": accessibility, affordability, and anonymity, es decir: accesibilidad, anonimato, asequibilidad. (Cooper, 1998).

Respecto a la accesibilidad, qué duda cabe que simplemente tecleando www.google.com y realizando una búsqueda utilizando palabras sexuales nos quedaríamos sorprendidos de lo que se puede encontrar sin cargos, sin control y sin límite de edad. Por ejemplo, WhiteHouse.Com es un sitio de pornografía, el verdadero sitio web de la Casa Blanca está en WhiteHouse.Gov. Añadido a ello, en muchos sitios web de pornografía está presente el backloading, una técnica utilizada en las páginas web para que una vez que se ha entrado no se pueda salir por los medios habituales sino que para ello haya que apagar el ordenador. Hay millones de sitios para adultos las 24 horas al día, 7 días a la semana. Adultos, niños, estudiantes, cualquiera que utilice la tecnología puede accidentalmente encontrar pornografía en línea y comenzar a navegar a través de millones de posibles imágenes desde la comodidad de sus hogares, oficinas y centros educativos. Además, se puede conectar con cientos de personas en los sitios de redes sociales como MySpace, Facebook o Twitter.

En relación con el anonimato, resulta interesante apreciar que incluso antes de entrar por primera vez en la red, nos sintamos incitados a jugar a adquirir falsas identidades, a transgredir los límites de género o a adoptar caracterizaciones variadas: violentas, amenas, fluidas. Se miente sobre edad, sexo, peso, etc. Sin consecuencias sociales, el comportamiento puede desinhibirse para lo social y lo sexual. Este anonimato facilita la comunicación abierta y franca con otros usuarios y puede aumentar la sensación de comodidad, porque hay una disminución de la capacidad para buscar y detectar los signos de sinceridad y desaprobación que sí se propician en la expresión facial, como ocurre en las relaciones interpersonales en vivo (Cooper \& Sportolari, 1997). La distancia que ofrece el ciberespacio permite a una persona compartir sentimientos íntimos, abriéndose la puerta a la intimidad y pudiendo llegar a vivir un affair en línea o cibersexo. Y por último, y en relación con la asequibilidad, las personas pueden pasar horas en la red en la intimidad de su propia casa participando en fantasías imposibles en la vida real. Correo electrónico, chat y foros públicos para permitir el anonimato y la comunicación sobre casi cualquier tema imaginable, hasta el más mínimo detalle. La competencia en la web mantiene los precios bajos, y hay muchas formas de acceso gratis al sexo.

Posteriormente, Young, Cooper, Griffin, Shelley, O'Mara, \& Buchanan (2000) desarrollaron una variante de la Triple A, lo que llamaron el ACE (anonimato, conveniencia y escape). Para estos autores el anonimato es una cuestión muy poderosa y una de las más seductoras atracciones del sexo en internet. El anonimato permite a los usuarios experimentar sexualmente, adquieren más confianza en la interacción anónima en contextos virtuales, la variedad de salas de chat de adultos y su contenido permite a los usuarios un entorno único para explorar fantasías ocultas o reprimidas, pueden adoptar nuevas personalidades en la red que difieren cualitativamente de las de la vida real y pueden usar internet como distracción para escapar de las dificultades y problemas en sus vidas.

En otro orden de cosas la seducción y la naturaleza adictiva de la red se explica principalmente en 
términos de un proceso de recompensa intermitente, que es el refuerzo más adictivo de todos, las líneas de alta velocidad en internet han revolucionado las recompensas. La sorpresa, la velocidad de la información, las imágenes y las visitas que se reciben son claves para generar compulsión y adicción. El tiempo vuela, siempre hay tiempo para un clic más, todo en internet puede convertirse en una aventura en relación con las oportunidades sociales, oportunidades que pueden ser leves o tremendamente estimulantes, y esto puede mejorar el estado de ánimo, la confianza y provocar una sensación de placer. Al igual que ocurre con el deseo de un cigarrillo o el deseo de tomar una copa, emociones como el estrés, la tristeza, la soledad, la ansiedad o el desgaste pueden conducir a un adicto a la necesidad de conectarse a internet, sirviendo como una distracción temporal para llenar un vacío emocional (Peele y Bronsky, 2000). En consonancia, los adictos al sexo en internet se sienten frustrados, preocupados, enojados, ansiosos y deprimidos cuando están desconectados y cuando se conectan a internet, se sienten entusiasmados, emocionados, desinhibidos, atractivos, apoyados y más deseables. Estas fuertes emociones positivas refuerzan la conducta compulsiva (Young, 1999). El comportamiento adictivo en sí actúa como una forma de evitar los sentimientos displacenteros de forma temporal, sirve para reducir la tensión emocional, un adicto al sexo en internet no usa el ordenador como una herramienta de información, sino como una herramienta para buscar un escape psicológico para hacer frente a sentimientos difíciles. Las personas que sufren una baja autoestima, que se sienten solos, ansiosos pueden utilizar el ciberespacio y conectarse con otros para sentirse mejor, tanto consigo mismos como con sus circunstancias. El sexo en internet ofrece un mundo de fantasía en el que hay un sinfín de personas que parecen ser interesantes y estar interesados en el otro. Para algunos jóvenes, con menos habilidades sociales puede resultar más fácil participar en ciber-relaciones que en la vida real. El adicto se vuelve cada vez más hacia este mundo de sombra, y siente a estos amigos como más reales que a su propio cónyuge o a los miembros de su familia. Internet se convierte temporalmente en un camino para el adicto pueda escapar de los problemas de la vida real. Con el tiempo, sin embargo, este mecanismo resulta improductivo y potencialmente dañino, la ocultación del comportamiento adictivo puede culminar en más problemas.

Aunque no todo el mundo se convierte en adicto a internet de la misma manera y por la misma razón, sí que existen algunas pautas generales para explicar esta conducta adictiva. La adicción al sexo en internet es un problema progresivo. Las conductas con el tiempo, se vuelven más frecuentes, más extremas o ambas cosas. Cuando la persona cree tener bajo control la adicción y este control se rompe, ya sea por una hora, una semana, un mes o un año, y vuelve de nuevo al mismo comportamiento a pesar de su promesa a sí mismo y a otros de que nunca volvería a hacerlo, a menudo suele sentir remordimiento por su fracaso y con gran determinación vuelve a otro periodo de abstención de la conducta hasta que esta resolución se debilita de nuevo y vuelve otra vez a aparecer, sin ayuda ésta es la forma en la que el ciberadicto vive su vida. (Carnes, 2003). El trastorno afecta a la capacidad de funcionar en el mundo real, el usuario aumenta su profundización cada vez más en la adicción hasta que la vida se convierte en completamente inmanejable. Los ciberadictos son un grupo oculto, la actividad la realizan en soledad, y creen que son los únicos que viven la locura del problema, no entienden por qué han caído en los hábitos de los chat o lugares que visitan, los grupos a los que se suscriben, o la naturaleza de los sitios porno que visitan, y se sienten impotentes para detenerlo (Delmonico, Griffin, \& Carnes, 2002). La adicción al sexo en internet puede clasificarse en cinco etapas sucesivas e interdependientes (Young, 2001). Serían el descubrimiento, la experimentación, la escalada, la compulsión $\mathrm{y}$, finalmente, la desesperanza. La progresión a través de las etapas y el cambio del uso al abuso puede ser gradual, o puede ocurrir de repente.

\section{Factores de riesgo}

Hay ciertas características de personalidad o estados emocionales que aumentan la vulnerabilidad psicológica a las adicciones. (Echeburúa, 1999): déficit de personalidad (introversión acusada, baja autoesti- 
ma y nivel alto de búsqueda de sensaciones); déficit en las relaciones interpersonales (timidez y fobia social); déficit cognitivo (fantasía descontrolada, atención dispersa y tendencia a la distracción); alteraciones psicopatológicas (adicciones químicas o psicológicas presentes o pasadas, depresión). En la adicción que nos ocupa los adolescentes y las personas que han visto reducida su movilidad por diferentes causas o son socialmente menos activos que en etapas anteriores tienen también mayores probabilidades.

Las personas más vulnerables son las mujeres y hombres que ya padecen depresión, desorden bipolar, ansiedad, autoestima baja, o las personas que tratan de recuperarse de una adicción anterior, muchos admiten abiertamente tener una personalidad adictiva y que previamente abusaron de la medicación, alcohol, tabaco o comida. El subgrupo de individuos que padecen adicción al sexo presenta un riesgo mayor para desarrollar una adicción a internet pues en el ciberespacio encuentran una manera de cumplir sus necesidades sexuales. Su único uso de internet es para conectarse a cibersexo o buscar ciberporno.

\section{Evaluación}

Además de identificar las señales de advertencia los terapeutas necesitaran instrumentos en las intervenciones para evaluar el tipo y la gravedad del problema. El psicólogo se ha de preguntar con este tipo de pacientes si se trata de un enlace virtual aislado, de un cyberaffair, de una adicción sexual, o de una codependencia entre una relación de dependencia y/o una adicción sexual en línea.

Es necesario evaluar al individuo, a su pareja, sus actividades en internet. Esta información se debería recoger a lo largo de cuatro dimensiones:

- Acción, el nivel de actividad directa (descarga de archivos, comunicaciones).

- Reflexión, la participación cognoscitiva que puede tener una calidad obsesiva.

- Emoción, el nivel relatado de emoción (sin arousal) y satisfacción por las actividades en línea.

- Arousal, a menudo acompañado por culpa asociada con las actividades en internet.
Una entrevista diagnóstica a lo largo de la dimensión de Acción debería incluir preguntas sobre el número de horas pasa en internet, y cuántas de ellas están relacionadas con búsquedas sexuales. El clínico debería ser consciente de la correlación entre el número de horas que permanece en internet entretenido con estas actividades y lo que ésto afecta a su vida. Uno de los primeros síntomas que se aprecia se refiere a la gran cantidad de tiempo que se pasa en actividades relacionadas con internet. En la evaluación debe determinarse si el incremento del uso de internet es algo normal por ser esta una herramienta nueva que causa una inicial fascinación, o por el contrario se ha convertido en una adicción, para ello resulta importante valorar el tiempo que hace en que se inició el problema. Los clínicos tienen que preguntar abiertamente sobre los distintos medios de comunicación en internet a los que están teniendo acceso (sitios Web, chats, correo electrónico, grupos de discusión, etc.), qué es lo que hacen concretamente y para qué los emplean.

¿Hubo una bajada del interés por el compañero sentimental, por la familia o los amigos?, ¿menor frecuencia en los contactos sexuales con el compañero?, ¿preocupación por internet, y dificultades concomitantes de concentración o en el trabajo? Son cuestiones a evaluar en la entrevista clínica. Intentar descubrir cómo se han limitado las redes de apoyo social, el grado de aislamiento y las dificultades encontradas en las relaciones sociales e íntimas. Estos aspectos son indicadores a menudo clave para aquellas personas vulnerables y con dificultades psicológicas. Como parte del proceso de evaluación y para encontrar respuestas a tales preguntas puede hacerse necesario entrevistar a un compañero o a otras personas significativas de su entorno.

Investigar el efecto cognoscitivo, sobre el pensamiento, la Reflexión. ¿Están preocupados por las experiencias pasadas vividas?, ¿piensan obsesivamente su última experiencia o planifican la siguiente?, ¿se hacen promesas a ellos mismos o a otros para dejar de usar internet y luego rompen estas promesas?, ¿tienen dificultades de concentración, con sus compromisos y responsabilidades en relación con la familia, los amigos, el trabajo, o la escuela? Después, indagar sobre la dimensión Emoción. ¿Se excitan con las búsquedas sexuales en internet? 
Estar atento si relatan que prefieren guardar en secreto sus actividades y el tiempo que emplean en ellas. Por lo general, el clínico con mucha probabilidad encuentre resistencia en esta línea de preguntas. No resulta insólito que tanto el secreto sobre las búsquedas como sobre el tiempo estén asociados con la vergüenza y la culpa, por lo que otra línea exploratoria está relacionada con el hecho de que la persona falsifique su identidad en internet. La cuarta línea de evaluación es el Arousal, es una línea difícil tanto para el terapeuta como para el paciente. Puede ser difícil para el terapeuta y embarazoso para el cliente admitir, el tipo y la naturaleza de sus preferencias sexuales y fantasías. Hay que preguntar si se masturban mientras permanecen en internet, o más tarde y si estas imágenes se incorporan en sus fantasías sexuales.

La experiencia clínica sugiere que la mayoría de los problemas asociados con la actividad sexual en internet giran en torno a la interferencia de este comportamiento con el matrimonio, las relaciones de pareja y otras relaciones importantes (Greenfield y Orzack, 2002). Otros autores han observado que los usuarios dependientes de internet poco a poco pasan menos tiempo con personas reales en sus vidas a cambio de tratar en solitario frente a un ordenador. (Shotton, 1991). En un estudio con 396 entrevistados adictos a internet afectados por la compulsión sexual en línea el 53\% informó de graves problemas de relación (Cooper, 1998), más de un $8 \%$ manifiestó signos de compulsividad sexual, el $32 \%$ reconoció que sus actividades sexuales en línea interferían en su vida, y el $22 \%$ relataban que sus actividades sexuales en línea habían puesto en peligro al menos una dimensión importante de su vida (Cooper, Scherer, Boies, y Gordon, 1999).

Por tanto, para evaluar a fondo adicción al sexo en internet es importante para el clínico prestar especial atención a si internet está siendo utilizado como un medio para lograr estimulación (excitación) y/o como un método para lograr la gratificación (el orgasmo), y específicamente de qué forma esta actividad está afectando a la vida del sujeto. Algunos usuarios justifican su comportamiento manifestando que utilizan el sexo virtual frente al real para alcanzar la excitación sexual, otros han eliminado la conexión con su cónyuge por completo
(Greenfield y Orzack, 2002). Con frecuencia los familiares y las parejas se sienten heridos, traicionados, rechazados, abandonados, destrozados, manifiestan celos e ira, así como pérdida de su autoestima cuando lo descubren, el hecho de ser engañados en repetidas ocasiones es la principal fuente de angustia, pudiendo llegar a compararse con las mujeres (u hombres) de las web y con las imágenes pornográficas, sentirse sin esperanza por no poder ser capaces de competir con ellos y llegar a considerar que los actos de sexo virtual constituyen un adulterio de la misma relevancia y magnitud que los actos de sexo en vivo con otra persona (Schneider, 2003). Esta distinción será útil para determinar el grado de impacto potencial en la vida real en sus relaciones y ayudar en relación con la excitación sexual y los trastornos del orgasmo.

\section{Consideraciones finales}

Como se ha señalado, resulta poco probable que las personas con adicción al sexo en internet lleguen a la terapia con este problema como su queja principal. Es muy frecuente racionalizar o negar la adicción a internet. A causa de la naturaleza obsesiva de sus comportamientos sexuales y el contenido vergonzoso de los mismos, los pacientes tienden a mentir y a evitar contar sus historias y acciones verídicas Un problema de adicción a internet puede emerger como una queja sobre un trastorno del sueño (bien porque no pueden dejar de descargar imágenes o por no querer terminar una sesión de Chat), como una amenaza o pérdida real de trabajo, como un problema de pareja, o incluso como un hecho delictivo (incluyendo el acoso sexual). Lo más frecuente resulta que sean las cuestiones relacionadas con los problemas de pareja el motivo principal para acudir a consulta.

El hecho de que exista una gran comorbilidad en este tipo de problemas complica la evaluación y el tratamiento, el terapeuta, si lo sospecha debe indagar sobre ello. Weiss (2004) cree que es imprescindible realizar un buen diagnóstico diferencial ya que esta patología puede presentar una alta tasa de comorbilidad con el abuso de sustancias y con otros trastornos. Young y Rogers (1998) estudiaron la posible 
existencia de una relación entre el uso problemático de la red y la depresión. En una investigación realizada a través de una página web hallaron que los sujetos que hacían un uso patológico de la red presentaban signos de depresión leve o moderada valorados a partir del Inventario de Depresión de Beck. En la misma línea, Kraunt et al. (1998) en un estudio realizado con 169 casos, encontraron una asociación entre el uso excesivo de internet, la sintomatología depresiva, la soledad, la disminución de las relaciones interpersonales y de comunicación con la familia, y un mayor aislamiento. La relación entre un alto uso de internet y el incremento en los niveles de depresión ha aparecido en varios estudios (Kraut et al., 1998; Petrie y Gunn, 1998; Young y Rodgers, 1998b). Sin embargo, existe aún mucha controversia sobre si la depresión es la causa o el efecto de la adicción a internet. Según Pratarelli et al., (1999), se produce un ciclo en el que la soledad y la depresión alimentan el uso del ordenador/ Internet lo que, a su vez, conlleva una mayor soledad y depresión, la cual la actividad de los usuarios se incrementa a medida que aumentan sus sentimientos de incomunicación.

Asimismo, Black, Belsare y Schlosser (1999) encontraron en un estudio que el $52 \%$ de los sujetos referían problemas escolares o académicos a causa del uso de ordenador, el $43 \%$ informaba de pérdidas laborales o académicas, el $38 \%$ referían problemas por abuso de sustancias y el $19 \%$ trastornos de ansiedad, el $52 \%$ de la muestra cumplía criterios para al menos un tipo de trastorno de la personalidad, siendo los más frecuentes el trastorno límite de la personalidad (24\%) y el trastorno antisocial (19\%). Los trastornos en el control de los impulsos también resultaron frecuentes, el 19\% eran compradores compulsivos y el $10 \%$ jugadores patológicos. En un estudio realizado por Yang (2001), con una muestra seleccionada de 1.296 adolescentes de entre 12 y 19 años, se halló que aquellos que hacían uso excesivo del ordenador $(6,1 \%$ del total de la muestra) presentaban además otra sintomatología asociada: obsesivo compulsiva (13\%), mayor sensibilidad interpersonal $(11,6 \%)$, somatización $(9,4 \%)$, ansiedad $(8,7 \%)$ y hostilidad $(8,7 \%)$.

En la medida que internet se vaya extendiendo y popularizando, también habrá más personas con problemas derivados de su uso inadecuado, por ello resulta necesario que los profesionales de la salud mental conozcan estos trastornos, que diseminen adecuadamente la información proporcionando marcadores para evaluar si el comportamiento de algunos individuos podría hacerlos vulnerables y desarrollar estudios, investigaciones y programas de prevención. Lamentablemente, la afición a internet es resistente al tratamiento, implica riesgos significativos y tiene altas tasas de recaída (Block, 2007). Además, la presencia de trastornos comórbidos hace que sea menos sensible a la terapia (Block, 2007). En general, los tratamientos se enfocan hacia la adicción a internet en sí, sin distinguir entre sus diversas modalidades, en este caso la sexual que es la que nos ocupa, y las técnicas y los programas cognitivo conductuales usados en otras adicciones son los que han mostrado evidencia científica.

\section{Referencias}

American Psychiatric Association. Diagnostic and statistical manual of mental disorders (4 ed., text revision). Washington: American Psychiatric Press; 2000.

Black, D. W., Belsare, G. \& Schlosser, S. (1999). Clinical features, psychiatric comorbidity, and health-related quality of life in persons reporting compulsive computer use behavior. Journal of Clinical Psychiatry, 60, 839-844.

Block, J. J (2007). Pathological computer use in the USA, in 2007 International Symposium on the Counseling and Treatment of Youth Internet Addiction. Seoul, Korea, National Youth Commission, 2007, 433.

Block J. J (2007). Lessons from Columbine: virtual and real rage. Am J Forensic Psychiatry, 28, 5-33

Block, J. J. (2008). Issues for DSM-V: Internet Addiction. Am J Psychiatry 165, 306-307.

Bowker, A., Gray, M. (2004). An Introduction to the Supervision of the Cybersex Offender . Federal Probation. 68, 3-8.

Búrdalo, B. (2000). Amor y Sexo en Internet. Madrid: Biblioteca Nueva.

Carbonell X., Guardiola, E., Beranuy M., Bellés A. A bibliometric analysis of the scientific literature 
on Internet, video games, and cell phone addiction, J Med Libr Assoc. 97, 102-107.

Carnes, P. J. (2003). The anatomy of arousal: Three internet portals. Sexual and Relationship Therapy, 18, 309-328.

Cavia B, Gordo A. (2002). Enredados en lo Virtual. Papeles del CEIC \# 5, (ISSN: 1695-6494) CEIC http://www.ehu.es/CEIC/papeles/5.pdf

Conner, M. G. (2008). Internet Addiction and Internet en http://www.helpguide.org/mental/ internet_cybersex_addiction.htm

Cooper, A. (1997). The Internet and sexuality: Into the next millennium. Journal of Sex Education and Therapy, 22, 5-6.

Cooper, A., \& Sportolari, L. (1997). Romance and cyberspace: Understanding online attraction. Journal of Sex Education and Therapy, 22, 7-14.

Cooper, A. (1998). Sexuality and the Internet: Surfing into the new millennium. Cyber Psychology \& Behavior, 1, 187-193.

Cooper, A., Scherer, C., Boies, S. C., \& Gordon, B. (1999). Sexuality on the Internet: From sexual exploration to pathological expression. Professional Psychology: Research and Practice, 30, 154-164.

Daneback, K., Cooper, Al., Mansson,S.-A. (2005). An Internet Study of Cybersex Participants. Archives of Sexual Behavior. 34, 321-328.

Delmonico, D. L., Griffin, E., \& Carnes, P. J. (2002). Treating online compulsive sexual behavior: When cybersex is the drug of choice. In A. Cooper (Ed.), Sex and the Internet: A guidebook for clinicians (pp. 147-167). New York: Routledge.

De Gracia M., Vigo M., Fernández, M. J., Marcó, M. (2002). Problemas conductuales relacionados con el uso de internet: un estudio exploratorio. Anales de Psicología, 18, 273-292.

Durkin, D. F., \& Bryant, C. D. (1995). Log on to sex: Some notes on the carnal computer and erotic cyberspace as emerging research frontier. Deviant Behavior, 16, 179-200.

Echeburúa, E. (1999). ¿Adicciones sin drogas? Las nuevas adicciones: juego, sexo, comida, compras, trabajo, internet. Bilbao: Desclee de Brower.

Eerikäinen, H. (2003). What is the "sex" in cybersex? On the desire for organs without a body? Zeitschrift für Sexualforschung 16. 328-361.
Elias Aboujaoude (2008). Anxiety Disorders Association of America 28th Annual Meeting: Oral Presentation 1C. March 6-9, 2007. Stanford University School of Medicine, California.

Galbreath, N. \& Berlin, F. (2002). Paraphilias and the Internet. In A. Cooper (Ed.), Sex and the Internet: Aguidebook for clinicians (pp. 187-205). New York: Brunner-Routledge.

Gelder, V. L. (1991). The strange case of the electronic lover (364-375). Academic Press.

Goldberg, I. (1995,07-04-2003): Internet Addiction disorder. Diadnostic criteria. Disponible en: http://www.iucf.indiana.edu/brown/hyplan/addict .html.

Greenfield, D. (1999). Virtual addiction: Help for netheads, cyberfreaks, and those who love them. Oakland, CA: New Harbinger.

Greenfield, D., \& Orzack, M. (2002). The electronic bedroom: Clinical assessment of online sexual problems and Internet-enabled sexual behavior. In A. Cooper (Ed.), Sex and the Internet: A guidebook for clinicians, New York: BrunnerRoutledge, 129-145.

Griffiths, M. D. (1998). Internet addiction: does it really exist? En J. Gackenbach (ed). Psychology and the Internet: Interpersonal, Interpersonal and Transpersonal Applications, New York: Accademic Press, 61-75.

Griffiths, M. (2001). Sex on the Internet: Observations and Implications for Internet Sex Addiction Nottingham Trent University Guberm, R. (2000). El Eros Electrónico. Madrid: Taurus.

Grohol, J. M. (1997,05-04-2003). Internet addiction disorder: An examination of the facts. Disponible en: www.cmhc.com/archives/editor22.htm

Grohol, J. M. (2008). Internet Addiction Guide. A resource for objective, useful information about Internet addiction, a theorized disorder. Is the Internet Addiction Test valid? February 2,1999, April 16, 2005, last reviewed: 21 Nov2008 en http://www.helpguide.org/mental/internet_ cybersex_addiction.htm

Instituto Nacional de Estadística (2008). Notas de prensa. Encuesta sobre Equipamiento y Uso de Tecnologías de Información. Comunicación en los Hogares.

Jaychandran, C. R. (2006). Porn rules net revenue 
charts. The Economic Times. Retrieved September 26, 2003, en http://economictimes.india times.com /cms.dll/xml/uncomp/articleshow? msid?203421.

Kraut, R., Patterson, M., Lundmark, V., Kiesler, S., Mukopahyay, T. \& Scherlis, W. (1998). Internet paradox: A social technology that reduces social involvement and psychological well-being? American Psychologist, 53, 1017-1031.

McKenna, K. Y. A., Bargh J.A. (1998). Coming out in the age of the internet: Identity "demarginalization" through virtual group participation. Journal of Personality and Social Psychology 75, 681-671.

Morahan-Martin, J. M. \& Schumacker, P. (1997). Incidence and correlates of pathological internet use. Articulo presentado en la 105th Anual Convention of de APA, Chicago, Illinois.

Organización Mundial de la Salud. CIE10. Trastornos mentales y del comportamiento. Descripciones clínicas y pautas para el diagnóstico. Madrid: Meditor; 1992.

Peele, S., \& Bronsky, A. (2000). Exploring psychological benefits associated with moderate alcohol use: A necessary corrective drinking outcomes. Drug Alcohol Dependency, 60, 249-250.

Petrie, H. \& Gunn, D. (1998): Internet "addiction": the effects of sex, age, depresión and introversion. Artículo presentado en la British Psychological Society London Conference.

Pratarelli, M. E., Browne, B. L. \& Jonson, K. (1999): The bits and bytes of computer/Internet addiction: A factor analytic approach. Behaviour research methods, instruments and computers, 31, 305-314.

Ramos, J. L. (2006). Los unos tienen pene y los ceros vagina: sexo y género en Internet en http://www.monografias.com/trabajos59/sexogenero-internet/sexo-genero-internet 2 .shtml.

Ropelato, J. (2006). Ropo Internet pornography statistics, Internet filters review top ten reviews. Retrieved April 13, 2006, from http://internet-filter-review.toptenreviews.com/internet-pornography-statistics.html.

Ross, M. (2005) Typing, doing and being: Sexuality and the internet. Journal of Sex Research. 42, 342-352.

Schneider, J. P. (2003). The impact of compulsive cybersex behaviors on the family. Sexual and Relationship Therapy, 18, 329-354.

Scheneider, J. P (2004). Editorial Sexual Addiction \& Compulsivity: Twenty Years of the Field, Ten Years of the Journal Sexual Addiction \& Compulsivity. 11, 3-5.

Shaw, M., Black D. (2008). Internet Addiction: Definition, Assessment, Epidemiology and Clinical Management. Leading Article CNS Drugs. 22(5), 353-365.

Shotton, M.A. (1991). The cost and benefits of "computer addiction". Behaviour Information and Techonology , 10, 219-230.

Weiss, R. (2004). Treating Sex Addiction Coombs, Robert Holman (Ed). (2004). Handbook of addictive disorders: A practical guide to diagnosis. and treatment. (pp. 233-272). Hoboken, NJ, US: John Wiley \& Sons, Inc. xvi, 584 pp.

Yang, C. K. (2001). Sociopsychiatric characteristics of adolescents who use computers to excess. Acta Psychiatrica Scandinavica, 104, 217-222.

Young, K. S., Rodgers R. C. (1998). The Relationship Between Depression and Internet Addiction. CyberPsychology \& Behavior, 1(1), 25-28.

Young , K. S., Rogers, R. C. (1998). The relationship between depresión and Internet addiction. Cyberpsychology and Behavior, 1, 25-28.

Young, K. S. (1999). Internet Addiction: symptoms, evaluation and tratament. En VandeCreek, L.\& Jackson, T. (Eds.). Innovations in clinical practice: a source book. Sarasota, F. L: Professional Resource Press.

Young, K. S., Pistner, M., O’Mara, J. y Buchanan, J. (1999). Cyber-Disorders: The mental health concern for the new millenium. Articulo presentado en el 107th Annual Meeting of the American Psychological Association, Boston, MA., 21 de Agosto de 1999.

Young, K., Cooper, A., Griffin-Shelley, E., O’Mara, J., \& Buchanan, J. (2000). Cybersex and infidelity online: Implications for evaluation and treatment. Sexual Addiction and Compulsivity, 7, 59-74.

Young, K. S. (2001). Tangled in the Web: Understanding cybersex from fantasy to addiction. Bloomington, IN: Authorhouse.

Manuscrito recibido: 10/11/2009

Revisión recibida: 26/11/2009

Manuscrito aceptado: 30/11/2009 